DOI: 10.20472/IAC.2018.038.007

\author{
NURAN BAYRAM ARLI \\ ULUDAG UNIVERSITY, Turkey \\ MINE AYDEMIR \\ ULUDAG UNIVERSITY, Turkey \\ NESE ARAL \\ ULUDAG UNIVERSITY, Turkey
}

\title{
SELF-ESTEEM, EMPATHY AND JEALOUSY IN THE WORKPLACE
}

\begin{abstract}
:
The purpose of this study is to examine the relationships among emotional states of self-esteem, empathy and employee jealousy in private sector employees using structural equation modeling. The study participants ranged in age from 28 years to 53 years, approximately $70 \%$ were male. The study group consisted of 216 employees. Printed questionnaires were sent to the entire private sector employees of a single fabric and were filled out anonymously. Relevant emotional states addressed in this study are self-esteem, empathy, and employee jealousy. A conceptual model was created in which self-esteem directly affects empathy and employee jealousy, and employee jealousy directly affects empathy. Then it was estimated by structural equation modeling. The results were $\chi 2 / d f=3.070 ; R M S E A=0.09 ; S R M R=0.09$. All the results are statistically significant. In particular, this study has shown that the self-esteem of employees is significant effects on the emotional states that can occur at work, such as empathy and employee jealousy. The employee jealousy plays a mediating role for self-esteem.
\end{abstract}

\section{Keywords:}

Self-esteem, Empathy, Employee Jealousy

JEL Classification: C10 


\section{Introduction}

Self-esteem is the disposition to experience oneself as competent to cope with the basic challenges of life and as worthy of happiness (Branden, 1994). On the other word self-esteem is a measure of how much you value, respect, and feel confident about yourself. Self-esteem is what we feel about ourselves. Positive self-esteem leads to a positive self-concept (mental health, quality of relationships, success, social effectiveness, happiness etc.) and negative selfesteem leads to a negative self-concept (anxiety, depression, psychosomatic symptoms, underachievement etc.). High self-esteem brings high respect for yourself, high ability to reach goals, high willingness to try new things and increased feelings of value. Individuals who have got low self-esteem have more unhealthy decisions. Low self-esteem brings high depression and suicide. At the same time these individuals more likely to be critical of self and others.

Empathy involves understanding another's feelings, thoughts, and wishes and then communicating this understanding back. Empathy allows us to achieve the best possible understanding of another's concern or perspective related to a given problem (Goldman, 1993). On the other word, empathy is the ability to identify and understand another person's situation, feelings and motives (Preece \& Ghozati, 2001). Empathy is the ability to put oneself in the shoes of another person. Ability to "read" the emotions and emotional states of others body language, voice and facial expressions. Studies show that high levels of empathy in the workplace will create a more productive environment, increase efficiency, promote a happy team environment and enhance communication.

Employee jealousy can define a pattern of thoughts, emotions, and behaviors that result from an employee's loss of self-esteem and/or the loss of outcomes associated with a working relationship (White and Mullen, 1989; Vecchio, 1995). The perceived threat of loss involves the perception of a rival's intrusion. This rival has the potential to reduce one's self-esteem or undermine a valued relationship (Wilcox, 2012). Jealousy is a powerful emotion, and in the workplace, it can potentially damage relationships, impede work progress and impact overall productivity. Jealousy is among the most painful of human emotions. The list of reasons to feel jealousy in the workplace is endless. Even those with a healthy dose of self-confidence may end up envious of a colleague every now and then. It doesn't always prevent jealousy in the workplace.

The aim of this study is to examine the relationships among emotional states of self-esteem, empathy and employee jealousy in private sector employees using structural equation modeling.

\section{Method}

\section{Study participants}

The study group consisted of 216 employees. Printed questionnaires were sent to the entire private sector employees of a single fabric and were filled out anonymously. 
Instruments

Emotional states of employees can affect that their experience at work. It also affects their performance. We used three different instruments to measure self-esteem, empathy, and employee jealousy.

To measure employee's Self-Esteem we used self-esteem scale developed by Rosenberg (1965). The reliability of the Turkish version of the scale was reported by Cuhadaroğlu (1985). High scores mean higher self-esteem levels.

To measure employee's empathy we used The Toronto Empathy Questionnaire (TEQ) scale developed by Spreng et al. (2009). The reliability of the Turkish version of the scale was reported by Totan et al. (2012). Higher scores mean higher empathic tendencies.

To measure Employee Jealousy we used a 5-point Likert scale developed by Vecchio (2000). The reliability of the Turkish version of the scale was reported by Bayram, Aydemir, Çelik (2018). This 5 -item questionnaire evaluates Employee Jealousy. High scores mean higher employee jealousy levels.

\section{Results}

The study participants ranged in age from 28 years to 53 years. The mean age was $37.79 \pm 4.47$ years, approximately $70 \%$ were male, and approximately $55 \%$ of the participants were married. $44 \%$ of the participants were university or college graduates.

Table 1: Means (M), Standard Deviations (SD), Correlations and Cronbach Alpha Values

\begin{tabular}{lccccc}
\hline Variables & $\mathrm{M}$ & $\mathrm{SD}$ & Self-Esteem & Emphaty & Jealousy \\
\hline Self-Esteem & 35.61 & 3.19 & .78 & & \\
Emphaty & 54.41 & 7.60 & $.624^{* *}$ & .86 & \\
Employee Jealousy & 10.81 & 3.64 & $-.421^{* *}$ & $-.513^{* *}$ & .80 \\
\hline
\end{tabular}

The Cronbach Alpha of each subscale was listed in the diagonal in boldface type. ${ }^{* *}$ indicates $p<0.01$

Table 1 show that mean, standard deviation, correlation and Cronbach Alpha values for scales. Cronbach Alpha values range between .78-.86. It means that these values are acceptable. There are a high and positive correlation between empathy and self-esteem $(r=.624 ; p<.01)$, high and negative correlation between employee jealousy and self-esteem $(r=-.421 ; p<.01)$ and high and negative correlation between employee jealousy and empathy $(r=-.513 ; p<.01)$. 
Figure 1: Structural Equation Model

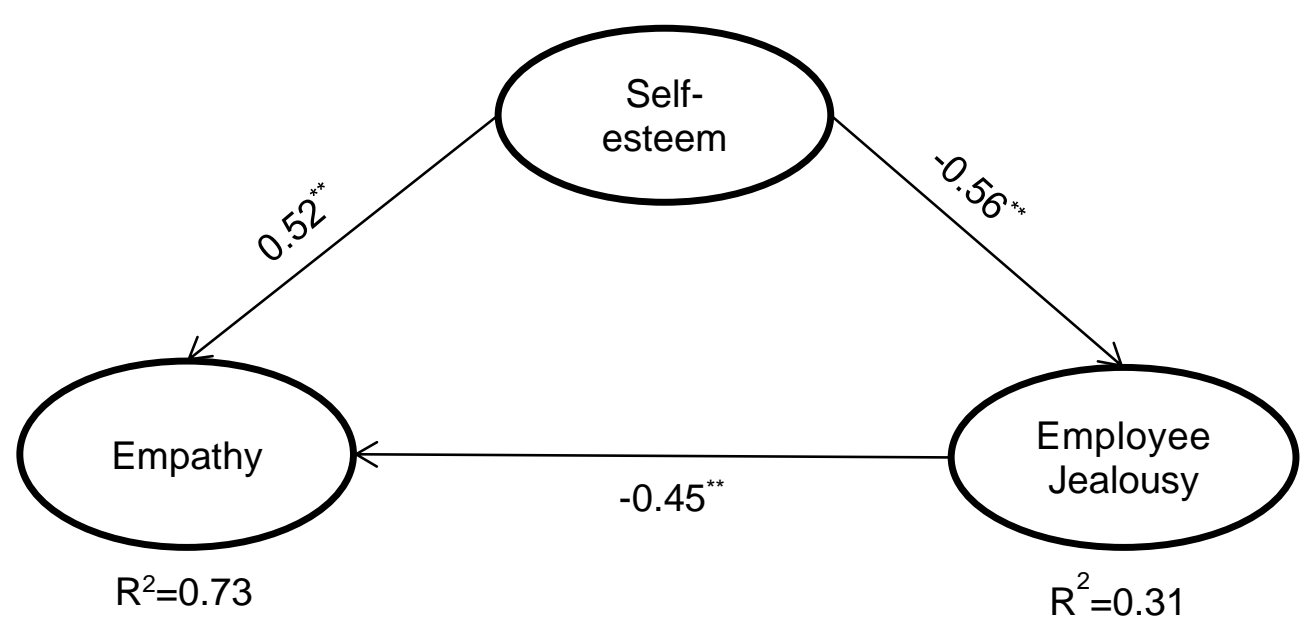

$X^{2} / d f=3.070 ; P G F I=0.63 ; R M S E A=0.09 ; S R M R=0.09$

In this figure, Structural Equation Model (SEM) showing standardized direct effects. A conceptual model was created in which self-esteem directly affects empathy and employee jealousy, and employee jealousy directly affects empathy. Then it was estimated by structural equation modeling. The results were $x 2 / d f=3.070 ; P G F I=0.63 ; \mathrm{RMSEA}=0.09 ; \mathrm{SRMR}=0.09$. The goodness of fit index values was acceptable.

\section{Conclusions}

The goodness of fit provided evidence that the hypothesized model was stable. All estimated path coefficients were significant. $73 \%$ of the variance in empathy was explained by the direct effect of self-esteem and employee jealousy. $31 \%$ of the variance in employee jealousy was explained by the direct effect of self-esteem. Structural equation model showed that self-esteem affects empathy positively $(\beta=0.52 ; p<.01)$, that self-esteem affects employee jealousy negatively $(\beta=-0.56 ; p<.01)$, and that employee jealousy affects empathy negatively $(\beta=-0.45$; $p<.01)$. All the results are statistically significant and the standardized coefficients are interpreted.

Laible et al. (2004), Ghorbani et al. (2010), Trumpeter et al. (2008) found that self-esteem had a positive relation with empathy. Vecchio, (2000) found that jealousy were significantly correlated with self-esteem. At the same time, Vecchio, (2000) and DeSteno et al. (2006) found that self-esteem affects employee jealousy negatively. These findings overlap with our findings. In particular, this study has shown that the self-esteem of employees is significant effects on the emotional states that can occur at work, such as empathy and employee jealousy. The employee jealousy plays a mediating role for self-esteem. 


\section{References}

BRANDEN, N (1994). The Six Pillars of Self-Esteem, New York: Bantam Books.

DESTENO, D., VALDESOLO, P. \& BARTLETT, M. Y. (2006). Jealousy and the Threatened Self: Getting to the Heart of the Green-Eyed Monster. Journal of Personality and Social Psychology, Vol. 91, No. 4, 626-641.

GHORBANI, N., WATSON, P. J., HAMZAVY, F., \& WEATHINGTON, B. L. (2010). Self-knowledge and narcissism in Iranians: Relationships with empathy and self-esteem. Current Psychology, 29(2), 135-143.

GOLDMAN, A. I. (1993). Ethics and cognitive science. Ethics, 103(2), 337-360.

GOLDMAN, A. I. (Ed.). (1993). Readings in philosophy and cognitive science. Mit Press.

LAIBLE, D. J., CARLO, G., \& ROESCH, S. C. (2004). Pathways to self-esteem in late adolescence: The role of parent and peer attachment, empathy, and social behaviours. Journal of adolescence, 27(6), 703-716.

PREECE, J., \& GHOZATI, K. (2001). Experiencing empathy online. The Internet and health communication: Experiences and expectations, 147-166.

SPRENG, R. N., MCKINNON, M. C., MAR, R. A \& LEVINE, B. (2009). The Toronto Empathy Questionnaire: Scale Development and Initial Validation of a Factor-Analytic Solution to Multiple Empathy Measures, Journal of Personality Assessment, 91:1, 62-71.

TRUMPETER, N. N., WATSON, P. J., O'LEARY, B. J., \& WEATHINGTON, B. L. (2008). Self-functioning and perceived parenting: Relations of parental empathy and love inconsistency with narcissism, depression, and self-esteem. The Journal of genetic psychology, 169(1), 51-71.

VECCHIO, R. P. (1995). It's not easy being green: Jealousy and envy in the workplace. In G. R. Ferris (Ed.), Research in Personnel and Human Resources Management, 13 (pp. 201-244). Greenwich, CT: JAI Press.

VECCHIO, R. P. (2000). Negative emotion in the workplace: Employee jealousy and envy. International Journal of Stress Management, 7(3), 161-179.

WHITE, G. L., \& MULLEN, P. E. (1989). Jealousy: Theory, research, and clinical strategies. New York: Guilford Press.

WILCOX, C. (2012). Envy: A Deeper Shade of Green. Xlibris Corporation. 